\title{
Questões de política de língua no Brasil: problemas e implicações
}

\section{Questions about language policy in Brazil: problems and implications}

\author{
Carlos Alberto Faraco*
}

\begin{abstract}
RESUMO
O presente artigo apresenta uma série de ponderações sobre questões de política lingüística no Brasil. Parte-se do confronto ideológico entre lingüistas e gramáticos da mídia para traçar alguns dos problemas da área e suas implicações.

Palavra-chave: política linguística.
\end{abstract}

\begin{abstract}
This article presents a series of reflexions on some topics of linguistic policy in Brazil. It refers to the ideological conflict between linguists and grammarians and delineates some of the problems in the area of language policy and its implications.

Key-word: linguistic policy.
\end{abstract}

As questões lingüísticas do Brasil são muitas e complexas. Para dar uma idéia geral dessa amplitude e complexidade, basta lembrar que o país é multilíngüe, mas em geral se reconhece como unilíngüe, confundindo hegemonia com unicidade. Neste sentido, a grande questão das centenas de línguas indígenas e aquela das dezenas de línguas de imigração (além

* Doutor em Lingüística pela Universidade de Salford, Professor do Programa de PósGraduação em Letras/UFPR. cfaraco@netpar.com.br 
dos preciosos resquícios de línguas africanas) não se configuram como um tema da nacionalidade e da cidadania. Em geral, prestamos pouca atenção a esse quadro complexo e, no mais das vezes, simplesmente damos de ombro para essa diversidade, seus significados e sua importância.

Por outro lado, a complexidade do quadro acima delineado aumenta ainda mais quando entra em cena a língua portuguesa. Para começar, temos aqui um discurso bastante contraditório: ao mesmo tempo em que se afirma, com orgulho, ser o Brasil um pretenso "milagre" lingüístico (isto é, um país em que todos supostamente falam a mesma língua em todos os rincões e, também supostamente, entendem-se plenamente), negase legitimidade social a vários falares brasileiros, que são menosprezados e até ridicularizados, com a conseqüente exclusão social dos grupos que os falam. Se o lado positivo desse discurso dá sustento, quando necessário, até a arroubos nacionalistas, seu lado negativo motiva, em geral, pesados preconceitos lingüísticos. Assim, no discurso corrente, o português é fator de unidade e orgulho, bem como de desdém e exclusão. Se é fator de unidade, é também fator de segregação.

Um outro aspecto merece consideração aqui: talvez como parte de um sentimento de inferioridade (seria herança de um passado colonial mal resolvido - aquele que nos fazia desejar ser uma nação branca e européia?), costumamos dizer que não sabemos falar português; que falamos mal a nossa língua. E o paradoxal aqui é que a régua desse julgamento são compêndios gramaticais cheios de artificialidade e anacronismo (ver a discussão em FARACO, 2002). Temos, assim, uma dificuldade histórica de entender nosso rosto lingüístico e de enfrentar positivamente o fosso entre um padrão cultivado e os padrões realmente praticados no país. Disso redundam enormes problemas para o ensino de português em todos os níveis, para os falantes em suas práticas de linguagem (em especial as escritas) e para a promoção interna e externa da língua.

Apesar dessa gama de problemas, a discussão política das questões lingüísticas é ainda muito reduzida e precária. No fundo, porque, apesar de sua dimensão e relevância social, elas não são ainda questões para a sociedade brasileira, isto é, elas não se apresentam como um problema de natureza política para o conjunto da sociedade, como algo que mereça controvérsia e debate.

Por isso, é sempre interessante aproveitarmos os momentos em que certas temáticas lingüísticas emergem e adquirem visibilidade, para desenvolvermos algumas reflexões no sentido de entender porque avançamos pouco nessa área tão relevante socialmente e como poderíamos eventual- 
mente alterar essa situação.

Nos últimos anos, questões lingüísticas voltaram a tomar corpo entre nós, principalmente a partir do ressurgimento dos consultórios gramaticais na imprensa. A velha fórmula difundida por Cândido de Figueiredo nos jornais dos fins do século XIX e começo do XX e por longos anos utilizada, por exemplo, por Napoleão Mendes de Almeida (em O Estado de São Paulo), voltou à cena com toda força.

Mas os grandes jornais foram adiante: não só abriram espaço para essas colunas, como definiram, em manuais de redação (que pouco fazem além de reproduzir acriticamente as velhas gramáticas), fatos de língua tidos como os únicos corretos e que, em princípio, seriam de uso obrigatório pelos seus redatores. As duas iniciativas tiveram inegável sucesso: os manuais tornaram-se best-sellers e os gramáticos da mídia viraram personalidades nacionais, em especial Pasquale Cipro Neto.

Esse duplo sucesso mercadológico levou alguns comentadores a ver aí uma vontade dos brasileiros de melhorarem seu conhecimento da língua portuguesa. Não nos interessa aqui duvidar dessa interpretação. Contudo, parece-nos relevante dar destaque a alguns aspectos que não são considerados por aqueles comentadores e que, segundo entendemos, precisariam ser melhor discutidos para sabermos se os consultórios e os manuais de redação respondem convenientemente àquela vontade de melhor conhecer a língua.

Os comentadores, por exemplo, não põem em dúvida, em nenhum momento, a eficácia da abordagem fragmentada dos fenômenos da língua que caracteriza os consultórios, isto é, nunca se perguntam se o trato disperso de questiúnculas gramaticais e normativas é procedimento apropriado para levar a um melhor domínio dos padrões.

Também não levantam nenhum questionamento sobre a justeza da concepção de língua que articula o discurso dos consultórios, isto é, sobre a língua entendida como um monumento monolítico, sem história, que precisa ser assumido como uma camisa de força pelos falantes. Igualmente, não levantam questionamentos sobre o anacronismo e artificialismo daquilo que é tomado como padrão. Ao contrário, dão o padrão de barato; assumem o padrão como algo dado de uma vez para sempre; não discutem o fosso entre o que se diz ser o padrão e os padrões efetivamente praticados no Brasil, mesmo nos casos em que o conflito é gritante.

Do mesmo modo, os comentadores não questionam se a fórmula da palmatória e da cultura do erro - o repisado pressuposto dos consultórios de que os brasileiros falam mal a língua e, por isso, precisam de um grande 
Pai Gramatical; e a caça contínua a erros - contribui, de fato, para diminuir as inseguranças dos falantes e para o aumento da nossa auto-estima lingüística.

Por fim, é preciso não esquecer o fato de que as normas estipuladas pelos manuais não são seguidas regularmente pelos redatores, isto é, há um fosso visível entre o texto dos jornais e aquilo que seus manuais definem como o padrão de língua. Como dar conta desse conflito? Poderíamos, talvez, culpar os redatores de negligência ou de despreparo. Contudo, um julgamento mais realista nos levaria a questionar, em primeiro lugar, a própria adequação daquelas normas, sem deixar de perguntar também pelas razões que levam os elaboradores dos manuais a simplesmente reproduzirem, sem crítica, as normas dos velhos compêndios gramaticais.

O fenômeno não é, portanto, simples como poderíamos imaginar à primeira vista. Por isso mesmo, vários lingüistas têm feito críticas sistemáticas aos consultórios gramaticais e aos manuais de redação dos jornais, críticas que se voltam basicamente para dois aspectos: o caráter anacrônico e artificial do padrão apresentado e defendido por eles e a concepção de língua aí presente. Para sustentar a primeira crítica, apelam para os dados obtidos por pesquisas da realidade lingüística brasileira que desmentem o caráter categórico de muitas das afirmações daqueles manuais e consultórios. São dados que apontam para a necessidade de rediscutir aberta e honestamente o que de fato caracteriza os padrões brasileiros orais e escritos.

Para sustentar a segunda, procuram mostrar que a concepção de língua que alimenta os manuais e os consultórios, além de ter o pressuposto genérico de que os brasileiros falam mal o português, não toma em consideração fatos fundamentais do funcionamento de qualquer língua humana, quais sejam: a variação lingüística, o encaixamento dos padrões no contexto dessa variação, os efeitos dos processos de mudança linguiística e as diferenças entre padrões falados e escritos.

Essas críticas, por mais fundamentadas que sejam, não resultaram, porém, na instauração de um frutífero e amplo debate público sobre a intrincada questão dos padrões brasileiros de língua. Aliás, esse tipo de debate é mais que necessário: não fosse por outra razão, pelo menos para melhor balizar o ensino de português, dando aos professores um referencial realista dos padrões que a eles cabe, em primeira instância, ensinar.

$\mathrm{O}$ que aconteceu nessa polêmica foi que o enfrentamento das partes acabou tomando, infelizmente, o caminho do mero descrédito mútuo dos adversários. Trocam-se farpas, ironias e xingamentos explícitos, ficando o 
que efetivamente interessa à margem dos debates. E é preciso reconhecer que a desvantagem na contenda está claramente do lado dos lingüistas, porque, entre outras razões, eles só dispõem dos espaços acadêmicos para expor seus pontos de vista não lhes sendo aberto na mídia o mesmo espaço reservado aos consultórios gramaticais. Quando muito é concedida aos lingüistas a oportunidade de aparecerem na seção de cartas.

Mas esse não é o ponto mais importante aqui. $\mathrm{O}$ fato de os lingüistas estarem sendo abertamente desqualificados na imprensa exige que aprofundemos as nossas reflexões. Há, na mídia, um discurso corrente que acusa os lingüistas de liberais ou relativistas que tudo admitem em língua (porque supostamente negam a relevância dos padrões, de seu ensino e de seu cultivo) e, portanto, não podem ser parceiros confiáveis da conversa. Os lingüistas já foram, inclusive, pintados como gente ociosa e inconseqüente e, mais recentemente, como esquerdistas de meia-pataca (porque supostamente idealizam tudo o que é popular e preconizam que os ignorantes continuem a sê-lo - cf. Veja, 7 nov. 2001, p. 112).

As causas dessa situação, evidentemente, são muitas. Talvez devêssemos começar pelo fato de que nós mesmos, profissionais de Letras e Lingüística, em geral, não costumamos dimensionar politicamente as nossas grandes questões. $\mathrm{O}$ acadêmico pelo acadêmico parece nos satisfazer. Talvez pelo fato de sermos (boa parte de nós, pelo menos) filhos e netos do pensamento estruturalista e formalista, continuamos, no fundo, a ser esses intelectuais de mente parnasiana, que sentem um certo incômodo, manifestam um certo desdém e até uma certa repulsa, sempre que, no trato das suas questões, devem entrar ingredientes sociais e culturais; sempre que é preciso entender essas questões em suas dimensões políticas.

Não podemos deixar de considerar, porém, que essa dificuldade de pensar politicamente não é exclusiva da área de Letras e Lingüística. Ela também tem a ver com o tradicional insulamento da instituição universitária e de suas práticas. Ora, esse insulamento, ao mesmo tempo que favorece a despolitização dos temas acadêmicos, também limita as possibilidades de diálogo dos acadêmicos com outras esferas da sociedade. Talvez por isso os lingüistas, especificamente no debate a que nos referimos acima, tenham tantas dificuldades para encontrar as estratégias retóricas adequadas à situação e ao tema; tenham tanta dificuldade para ganhar o espaço público como parceiros do debate.

Nos aferramos à lógica do debate acadêmico e acreditamos ser suficiente, para defender nossos pontos de vista, lançar mão do rigor da demonstração silogística. Não nos damos conta, porém, que o embate 
está ocorrendo num outro terreno, isto é, no poderoso terreno das crenças e do imaginário social sobre a língua. Desse modo, o apelo à pura racionalidade científica convence pouco o público em geral, porque as asserções e formulações científicas costumam ser, em boa parte, contra-intuitivas, isto é, o que se pode dizer cientificamente sobre as dimensões estruturais, sociais e históricas do lingüístico fere profundamente as crenças e valores correntes na sociedade. E, aqui, por todas as razões, as pessoas preferem a segurança de suas crenças e valores (como, aliás, em muitas outras áreas em que o discurso científico e o senso comum entram em conflito), ainda mais se o próprio embate, não sendo ainda uma questão coletiva, não faz nenhum sentido para elas.

Que sentido faz, por exemplo, dizer para o público em geral que uma língua não existe como uma realidade una e homogênea, mas que aquilo que designamos por um único nome é, de fato, um espectro de variedades, se o senso dos falantes (pelo menos nas culturas como a nossa) lhes diz o contrário?

Que sentido faz demonstrar que as variedades se equivalem do ponto de vista estrutural, se os falantes interpretam a diversidade com base no princípio de que há uma língua certa e todo o resto é errado?

Que sentido pode fazer para os falantes argumentar que as línguas humanas têm plenitude estrutural e, portanto, não se "desmancham" (embora se transformem continuamente no eixo do tempo), se o discurso corrente lhes apresenta a língua como em franco processo de deterioração pelo descuido e menosprezo deles próprios?

Que sentido faz dissertar sobre o fato de que todas as línguas humanas são híbridas (porque as culturas humanas são híbridas), se o discurso social dominante, de tempos em tempos, diz que é preciso defender uma suposta pureza da língua?

Que sentido faz apresentar a língua como fenômeno em contínua mudança (e as conseqüências disso), se o senso dos falantes a percebe como uma realidade estática?

Ainda: que sentido faz argumentar que não há um único padrão; que o padrão apresentado nos compêndios gramaticais é artificial e anacrônico; e que os padrões são construídos historicamente, se a comunidade acredita que só há um padrão e que este padrão é a própria língua?

A resignação e a acomodação devem ser, então, as únicas alternativas que restam para os profissionais de Letras e Lingüística? Nada lhes cabe fazer, não obstante o tamanho dos problemas lingüísticos do país? O espaço público deve mesmo permanecer restrito aos gramáticos 
da mídia, na medida em que só eles parecem responder às demandas de certa parcela da população e só neles se pode confiar, porque só eles reiteram as crenças correntes?

Considerando a relevância social e cultural da construção de novas políticas lingüísticas para o país, é certamente difícil aceitar que só resta aos profissionais de Letras e Lingüística responder afirmativamente a estas últimas questões. No entanto, respondê-las negativamente é também se pôr diante de um desafio enorme, cheio de muitas e complexas faces.

Há primeiramente a necessidade de se politizar as questões no próprio universo acadêmico. Para se ter uma idéia das dificuldades nesse ponto, é interessante fazer referência a um fato bastante exemplar. A Associação Brasileira de Lingüística (Abralin), durante a gestão 97/99, encaminhou um debate interno sobre bases de uma definição de políticas linguiísticas para o país. Daí resultou um documento preliminar, mas importante como forma de motivar e contribuir para balizar as discussões dessa temática.

Esse documento sintetiza, mesmo que ainda de forma genérica (mas com bastante propriedade), as principais características do rosto lingüístico do Brasil; introduz o importante conceito de direitos lingüísticos do cidadão, comenta pontos de resistência à elaboração de políticas lingüísticas e, por fim, arrola algumas iniciativas que poderiam levar os debates para além do contexto dos especialistas.

Esse documento, infelizmente, não teve ainda maiores repercussões. Em grande parte, isso se deve ao fato de a própria entidade o ter divulgado pouco. E não só isso: paradoxalmente, ele desapareceu até da própria página da entidade, de tal modo que, hoje, não há meio de conhecê-lo!

Temos ainda, portanto, de conquistar nossa própria área para o debate político das questões lingüísticas. Além disso, será preciso encontrar os meios adequados para sair do espaço intramuros, o que inclui a busca de caminhos que favoreçam a ampliação e o enriquecimento do debate público.

Neste sentido, é preciso ter claro que, enquanto as questões lingüísticas não forem entendidas como um problema de fato para a sociedade, o debate público tenderá a permanecer restrito e pobre. Claro que, desse modo, não se criam espaços para que múltiplos pontos de vista sobre essas questões e suas contradições apareçam. Ora, quando não é possível confrontar publicamente múltiplos planos interpretativos, fecha-se também a possibilidade da elaboração e reelaboração histórica dos sentidos; fecha-se também a possibilidade de crítica aos discursos dominantes, o que redunda na neutralização da própria prática política. 
Desse modo, talvez, de saída, uma das coisas que deveríamos querer como profissionais de Letras e Lingüística é contribuir para que se democratize a circulação de todos os discursos no espaço público.

Democratizar a circulação de todos os discursos não é, evidentemente, tarefa fácil. Acreditamos que há, pelo menos, três grandes espaços públicos que poderiam e deveriam contribuir para isso; que poderiam e deveriam - para usar palavras do escritor Mário de Andrade - pôr em marcha, pôr em evidência os problemas embutidos na questão "língua". E esses espaços são: (a) a escola básica (abrangendo a educação fundamental e média); (b) a universidade; e (c) a imprensa.

A educação básica está entendida aqui - talvez meio utopicamente como o espaço republicano privilegiado da repartição entre todos dos bens culturais; e da construção de um patamar coletivo mínimo de referências, entre as quais deveria estar - além do domínio das práticas orais e escritas de linguagem - a compreensão crítica do funcionamento social da linguagem.

Ora, a escola brasileira, como todos sabemos, nunca conseguiu garantir à população escolar em seu todo, mesmo depois da expansão do sistema escolar nas últimas décadas, o domínio das práticas de linguagem (salvo para pequenos grupos sociais) e, ao que tudo indica, está cada vez mais distante de poder fazê-lo, considerando seu esgarçamento como instituição. E nunca foi tema da escola uma discussão crítica sistemática das grandes questões lingüísticas nacionais, o que não é de se estranhar, considerando que essas nem mesmo são questões para a sociedade, como vimos acima.

No caso específico do ensino de língua portuguesa, apesar dos debates dos últimos 50 anos e das sucessivas mudanças retóricas nos discursos pedagógicos oficiais, a escola fundamental e média continua perdida na gramatiquice e no normativismo (ver FARACO, 2002, no prelo). Neste sentido, parece que estamos longe ainda de ver a escola contribuindo efetivamente para pôr as questões lingüísticas em evidência. No fundo, o longo debate de 50 anos, ao que tudo indica, não conseguiu mexer com crenças e valores sociais e escolares. Novamente, parece claro que a retórica acadêmica tem sido pouco eficaz.

Quanto à universidade, temos de reconhecer que o Brasil conseguiu, nos últimos 25/30 anos, construir, na área de Letras e Lingüística, um razoável sistema de pós-graduação que inclui centros de boa qualidade, alguns inclusive capazes de se equiparar a grandes centros científicos internacionais. 
Isso favoreceu a disseminação dos saberes teóricos e também o desenvolvimento de projetos de descrição do português e dos outros componentes da complexa realidade lingüística brasileira: temos ampliado um programa de pesquisas em línguas indígenas e construímos vários bancos com dados do português, os quais têm permitido descrições de diferentes modalidades faladas por aqui, inclusive em contextos bilíngües.

Apesar disso, como destacamos acima, continuamos muito insulados e isolados da sociedade. Bastaria lembrar, neste sentido, por exemplo, que são raros aqueles que na universidade se sentem atraídos pelas atividades de divulgação científica ou de extensão universitária, que são indispensáveis se queremos que nossas vozes circulem socialmente.

A imprensa, por seu turno, que poderia ser um precioso espaço para a ampliação e o enriquecimento do debate público, raramente tem conseguido abrir-se para temas lingüísticos. Assim, a polêmica que ocorreu entre nós e o deputado proponente do projeto de lei 1676/99, de março a julho de 2001, nas páginas do caderno Mais! da Folha de São Paulo, embora muito salutar, foi certamente uma exceção.

No geral, é pouco comum que um jornal se disponha a ir além de uma visão estereotipada da língua, que, no Brasil, no caso da língua portuguesa, caracteriza-se por um purismo mal digerido. E isso, de certa forma, é bastante paradoxal, porque os jornalistas têm formação universitária. A universidade, nesse caso, parece que não consegue fazer circular dentro dela mesma o saber que produz. Em conseqüência, os jornais e demais meios de comunicação social têm se caracterizado pelo discurso único sobre questões lingüísticas e dão espaço quase exclusivamente a seus gramáticos. Mesmo a imprensa mais especializada - como a revista Cult - não consegue encarar um debate mais arejado da questão da língua.

Desse modo, dois espaços sociais que deveriam ser aliados na promoção da cultura lingüística têm vivido, equivocadamente, como adversários.

Com esses espaços enroscados politicamente, não é de admirar que continuemos um país que não consegue sequer reconhecer sua cara lingüística no espelho; que dirá discutir mais adequadamente políticas de língua.

Ora, sem o enfrentamento político dessas muitas questões, fica também quase inviável querermos conduzir, por exemplo, um debate mais consequiente sobre o ensino de português no Brasil. Boa parte dos problemas desse ensino não é obviamente apenas de natureza didático-pedagógica ou de fundamentos científicos. Alguns de seus grandes entraves derivam, an- 
tes de tudo, do próprio fato de que a sociedade brasileira não foi capaz ainda de abrir um amplo debate político sobre suas grandes questões lingüísticas.

\section{REFERÊNCIAS}

MORAES, M. A. de (Org.). Correspondência Mário de Andrade \& Manuel Bandeira. São Paulo: Ed. da USP, 2000. (Coleção Correspondência de Mário de Andrade, 1).

FARACO, C. A. A questão da língua: revisitando Alencar, Machado de Assis e cercanias. Linguas e instrumentos lingüísticos, Campinas, n. 7, p. 33-51, 2002.

. Ensinar ou não ensinar gramática: ainda cabe essa questão? No prelo (a sair em 2002, em livro organizado por Paulo Guedes, sobre ensino de português, pela Editora da UFRGS).

Texto recebido em 22 jul. 2002

Texto aprovado em 26 ago. 2002 